\title{
CONF-98040Z--
}

Computational Physics and Engineering Division

\section{Dose Consequences From a Postulated Criticality Occurring in a Low-Level Waste Disposal Facility}

\author{
B. L. Broadhead, R. L. Childs, C. M. Hopper, and C. V. Parks \\ Oak Ridge National Laboratory* \\ P.O. Box 2008 \\ Oak Ridge, Tennessee USA 37831-6370 \\ PECEIVED \\ FEB 251938 \\ OSTI \\ Submitted for the \\ ANS 1998 Radiation Protection and Shielding Division Topical Conference \\ Technologies for the New Century \\ April 19-23, 1998 \\ Nashville, Tennessee, USA
}

\section{6}

The submitted manuscript has been authored by a contractor of the U.S. Government under contract No. DE-AC05-96OR22464. Accordingly, the U.S. Government retains a nonexclusive, royalty-free license to publish or reproduce the published form of this contribution, or allow others to do so, for U.S. Government purposes.

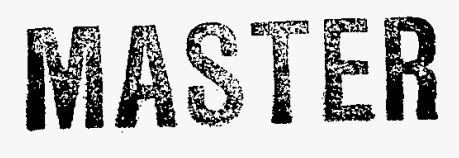

"Managed by Lockheed Martin Energy Research Corp. for the U.S. Department of Energy under contract DE-AC05-96OR22464. 


\section{DISCLAIMER}

This report was prepared as an account of work sponsored by an agency of the United States Government. Neither the United States Government nor any agency thereof, nor any of their employees, makes any warranty, express or implied, or assumes any legal liability or responsibility for the accuracy, completeness, or usefulness of any information, apparatus, product, or process disclosed, or represents that its use would not infringe privately owned rights. Reference herein to any specific commercial product, process, or service by trade name, trademark, manufacturer, or otherwise does not necessarily constitute or imply its endorsement, recommendation, or favoring by the United States Government or any agency thereof. The views and opinions of authors expressed herein do not necessarily state or reflect those of the United States Government or any agency thereof. 


\title{
Dose Consequences from a Postulated Criticality Occurring in a Low-Level Waste Disposal Facility
}

\author{
B. L. Broadhead, R. L. Childs, C. M. Hopper and C. V. Parks \\ Oak Ridge National Laboratory \\ P.O. Box 2008 \\ Oak Ridge, Tennessee USA 37831-6370
}

\begin{abstract}
Evaluations were done to determine conditions that could permit nuclear criticality with fissile uranium in low-level-waste (LLW) facilities and to estimate potential radiation exposures to personnel if there were such an accident. Simultaneous hydrogeochemical and nuclear criticality studies' ${ }^{\prime}$ were done (1) to identify realistic scenarios for uranium migration and concentration increase at LLW disposal facilities, (2) to model groundwater transport of uranium and subsequent concentration via sorption or precipitation, (3) to evaluate the potential for nuclear criticality resulting from potential increases in uranium concentration over disposal limits, and (4) to estimate potential radiation exposures to personnel resulting from criticality consequences. This paper presents the details of the radiation exposure calculations relying on the conditions as determined from the preceding studies detailed in Ref. 1.
\end{abstract}

\section{INTRODUCTION}

Many combinations of variables may support nuclear criticality in a waste matrix, herein called soil, and will influence a radiation dose determination. These variables include:

- the composition of the soil (e.g., $\mathrm{SiO}_{2}$, concrete debris, contaminated combustibles, iron scrap, etc.);

- the enrichment of ${ }^{235} \mathrm{U}$ mass compared with the total uranium mass (e.g., less than $5 \mathrm{wt} \%{ }^{23} \mathrm{U}$ from commercial power reactor fuel fabrication processes, approximately $93 \mathrm{wt} \%{ }^{233} \mathrm{U}$ for research reactor fuel or weapons fabrication processes, $0.7 \mathrm{wt} \%{ }^{235} \mathrm{U}$ for natural uranium processes, less than about $0.2 \mathrm{wt} \%{ }^{235} \mathrm{U}$ from enrichment process tails);

- the density of the soil (e.g., grams of compacted debris per cubic centimeter, tons of compacted debris per cubic yard);

- the density of the ${ }^{235} U$ within the soil (e.g., grams of ${ }^{235} U$ per cubic centimeter);

- the degree of neutron moderation in the soil (e.g., typically grams of $\mathrm{H}_{2} \mathrm{O}$ per cubic centimeter, grams of $\mathrm{H}_{2} \mathrm{O}$ per gram of soil, hydrogen to ${ }^{235} \mathrm{U}$ atom ratios);

- the degree of neutron reflection (e.g., thickness and density of reflecting materials such as concrete, soil, moist or saturated soil);

- the geometry or distribution of the ${ }^{235} U$ in the soil (e.g., neutronically infinite deposits, finite geometries typically characterized as spheres, infinite-length cylinders, and finite thickness slabs of infinite length and width); and

- the neutronic interaction of one deposit with another deposit of similar or dissimilar characteristics.

The ranges of the above variables were selected from historic records, state license conditions, ${ }^{2}$ and naturally occurring environmental conditions at the Envirocare of Utah, Inc., Clive, Utah, LLW facility. In certain cases, the selection of these parameters differed between the criticality and radiation protection scenarios, e.g., water was removed to minimize its shielding benefit.

*Managed by Lockheed Martin Energy Research Corp. for the U.S. Department of Energy under contract DE-AC0596OR22464. 


\section{CONSIDERED EVALUATIONS}

\section{NUCLEAR CRITICALITY}

Criticality evaluations are key to this work since they determine the qualitative probability of the dose consequence occurrence. The nuclear criticality evaluations began with the State of Utah license condition for ${ }^{23} \mathrm{U}$ contaminated waste (i.e., $770 \mathrm{pCi}$ of ${ }^{235} \mathrm{U}$ per gram of soil-like waste) at the Envirocare facility in Clive, Uthh. Because no license condition restricts the wt $\%{ }^{23} \mathrm{U}$, the nuclear criticality evaluations considered $100 \mathrm{wt} \%$ enriched uranium (i.e., pure ${ }^{235} U$ ) to safely envelop lesser uranium enrichments.

Homogeneous, one-dimensional (1-D) bounding and simplifying computational assumptions were used for the nuclear criticality evaluations of the various parameters. Nuclear criticality evaluations were done for simple finite-media geometries and infinite media assuming various densities of ${ }^{235} \mathrm{U}$ and water for two generic soil media (both having a dry and uncontaminated density of $1.6 \mathrm{~g}$ of soil media per cubic centimeter): pure " $\mathrm{SiO}_{2}$ soi" and a "nominal soil" composed of minerals and secondary phases representative of a world-average soil composition. ${ }^{3}$ The infinite-media neutron-multiplication constant, $\mathrm{k}_{-}$, was determined for mixtures of nominal soil/235/water and $\mathrm{SiO}_{2}$ soil/235 U/water. Additionally, sphere diameters, infinitely long cylinder diameters, and thicknesses of slabs (infinite in two dimensions) were determined for finite-media geometry neutron-multiplication constants, $\mathbf{1}_{\text {a }}$ equal to a fiducial "critical" value of 0.95 . The value of 0.95 , rather than 1.0 , was selected as a critical value to account for methods and data uncertainty conservatively. The finite-media geometry calculations included a 2-m-thick "neutron reflector" on the surfaces of each type geometry. The neutron reflector consisted of uncontaminated soil having an identical water content as that of the contaminated soil. The calculations were done with XSDRNPM, a 1-D discrete-ordinates neutron transport theory deterministic code in SCALE. ${ }^{4}$ XSDRNPM was executed by the CSAS module to provide the infinite-media neutron multiplication constant, $\mathbf{k}_{-}$, and the finite-media neutron multiplication constant, $k_{\text {eff }}$ values reported in this study. Problem-dependent processing of the 238-energy group ENDF/B-V cross sections, to account for temperature effects and resonance self-shielding, was performed using the NITAWL and BONAMI codes. SCALE was used in the calculation of benchmarks and applications analyses.

Two sets of realistic geologic parameters were considered for various densities of ${ }^{235} U$. Calculated critical densities of ${ }^{235} \mathrm{U}$ for various finite-media geometries were translated into concentration factors (CF) (i.e., the ratio of the required ${ }^{235} U$ density to sustain criticality divided by the maximum authorized ${ }^{235} U$ density allowed for burial at Envirocare of Utah, Inc.). These CFs were then compared with results from the hydrogeochemical modeling to learn if criticality is plausible for various uranium-concentrating hydrogeochemical scenarios.

\section{CONSEQUENCE EVALUATION}

The actual number of fissions that occur (the so-called fission yield) is a difficult quantity to determine. The approach taken in this study was to assume that the concentration of fissile material occurs under wet conditions, followed by a dry-out period during which the critical conditions are initiated and continue untin the event is terminated due to the evaporation of the full inventory of water. Using a widely accepted rule of thumb that $10^{17}$ fissions are required to boil $1 \mathrm{~L}$ of water, ${ }^{3}$ the amount of water present under the various cases was used to estimate postulated fission yields.

Direct-dose radiation transport calculations were done to estimate the neutron and gamma radiation doses near the soil surface as a consequence of two postulated critical configurations at differing uranium concentration values - one at the near-minimum ${ }^{235} \mathrm{U}$ critical density and the other at the near-maximum ${ }^{235} U$ density. Both configurations were assumed to be large-diameter (i.e., $18 \mathrm{~m}$ ), disklike cylindrical deposits of overly watermoderated uranium in $\mathrm{SiO}_{2}$ (the water was removed for dose estimation). Both configurations were vertically centered in a trench. The first postulated critical configuration was an 18 -m-diam disk that was approximately $2.5 \mathrm{~m}$ in thickness, which corresponds to a CF of about 3.6. The second postulated critical configuration was an 18-m-diam disk that was approximately $0.9 \mathrm{~m}$ in thickness, which corresponds to a CF of about 10.5 .

The direct-dose evaluations were performed for two different locations, both at $1 \mathrm{~m}$ above the ground surface, for both critical configurations. The first location was directly above the center of the cylindrical deposit, and the second location was $90 \mathrm{~m}$ from the first.

The calculations were performed using the DORT ${ }^{6}$ code that solves the two-dimensional (2-D) discreteordinates radiation transport equations. The DORT calculations used the SCALE coupled 27-neutron and 18-gamma group cross sections. The code was used in a two-step procedure for computational efficiency. The first step solved an effectively 1-D criticality problem to obtain the size and energy distribution of the neutrons and gamma rays leaking through the ground above the deposit. The second step solved the 2-D air-over-ground 
problem with the leakage source (a tabulation of the neutrons/gamma rays leaking from the ground) from the first step. A dose consequence profile was obtained corresponding to $1 \mathrm{~m}$ above ground surface directly over the center of the assumed deposit to $90 \mathrm{~m}$ away from the vertical centerline of the assumed deposit.

\section{RESULTS OF EVALUATIONS}

Examinations of hydrogeochemical modeling simulations and criticality safety evaluations showed that, based on historical operations, increasing uranium concentration to levels of concern is not expected within known commercial LLW sites with uranium blended with soil. However, obtaining levels of concern for current authorized disposal limits is theoretically possible (based on 1-D hydrogeochemical models). The theoretical potential for criticality concern is expected since in nature it is observed that uranium ores occur and soil-forming processes concentrate other elements. What is useful about this work is that it examined the potential effects of hydrogeochemical concentrating influences and their results on the nuclear criticality safety of various concentrations of LLW fissile material disposal configurations (i.e., effectively infinite and finite spherical, cylindrical, and planar type geometries).

\section{CRITICALITY EVALUATION RESULTS}

Limited criticality results are provided in Table 1 for " $\mathrm{SiO}_{2}$ soil" type. It was shown previously' that the critical parameters for "Nominal-Soil" are only about 1.5 times larger than "SiO ${ }_{2}$-Soil" systems having similar ${ }^{233} \mathrm{U}$ and $\mathrm{H}_{2} \mathrm{O}$ concentrations. This is to say that "real-world" soil compositions may provide only minor improvements to system subcriticality.

Another observation from this study is that critical slab-like configurations are more readily achieved by homogeneous hydrogeochemical processes than cylindrical configurations. Likewise, a critical cylindrical configuration is more readily achieved than a spherical configuration. For instance, an infinite slab of $\mathrm{SiO}_{2}$ soil at $0.0063 \mathrm{~g} \mathrm{of}{ }^{233} \mathrm{U} / \mathrm{cm}^{3}$ is critical at an areal density of $3.156 \mathrm{~kg}$ of ${ }^{235} \mathrm{U} / \mathrm{m}^{2}$ in a planar configuration. However, the ${ }^{235} \mathrm{U}$ linear density of the infinite horizontal cylinder requires a projected areal density of about $4.85 \mathrm{~kg}$ of ${ }^{235} \mathrm{U} / \mathrm{m}^{2}$ (i.e., $4.748 \mathrm{~kg}$ of ${ }^{25} \mathrm{U} / 0.9796 \mathrm{~m}^{2}$ of projected area). Thus, achieving criticality in a cylindrical geometry under the same conditions as the slab-like configuration requires substantial lateral migration as well as vertical migration of the ${ }^{235} U$. Achieving criticality in a spherical geometry requires a projected areal density of about $5.87 \mathrm{~kg}$ of ${ }^{235} \mathrm{U} / \mathrm{m}^{2}$ (i.e., $9.106 \mathrm{~kg}{ }^{235} \mathrm{U} / 1.55 \mathrm{~m}^{2}$ of projected area ), a density that requires significant lateral migration of ${ }^{23} \mathrm{U}$. In summary, a unidirectional migration of special nuclear material (SNM) into a slab-like configuration requires less concentration of ${ }^{235} \mathrm{U}$ to pose nuclear criticality safety concerns than do cylinders and spheres.

\section{CONSEQUENCE EVALUATION RESULTS}

A slab-like disk deposit of $18-\mathrm{m}$ diam was the assumed geometry for the postulated critical systems. Two extreme circumstances were considered for estimating fissions yields. Both circumstances were constrained by the limiting disposal areal density (i.e., about $5.7 \mathrm{~kg}{ }^{23} \mathrm{U} / \mathrm{m}^{2}$ given the limiting disposal value of $700 \mathrm{pCi}^{23} \mathrm{U} / \mathrm{g}$ of soillike waste, using a dry, uncontaminated soil density of $1.6 \mathrm{~g} \mathrm{soil} / \mathrm{cm}^{3}$, and a $10-\mathrm{m}$ trench depth). The first circumstance was a $250-\mathrm{cm}$-thick disk deposit at a low concentration factor (LCF) condition (i.e., 3.6 times the allowable disposal density, or $0.002154 \mathrm{~g}^{235} \mathrm{U} / \mathrm{cm}^{3}$ of soil at $1.6 \mathrm{~g} \mathrm{soil} / \mathrm{cm}^{3}$ ) that was the apparent minimum critical concentration that would initiate a criticality accident in an overly moderated condition and stop upon drying. The second circumstance was a 94-cm-thick disk deposit with a high concentration factor (HCF) condition (i.e., 10.5 times the allowable disposal density, or $0.0063 \mathrm{~g}^{233} \mathrm{U} / \mathrm{cm}^{3}$ ) that was the apparent maximum critical concentration that would initiate a criticality accident in an overly moderated condition and end upon drying.

Given the considered two extreme ${ }^{235} \mathrm{U}$ densities (i.e., $\mathrm{LCF}=0.00215 \mathrm{~g}^{235} \mathrm{U} / \mathrm{cm}^{3}$ and $\mathrm{HCF}=0.0063 \mathrm{~g}$ ${ }^{235} \mathrm{U} / \mathrm{cm}^{3}$ ), the concomitant water content in the soil (about $0.0444 \mathrm{~g} \mathrm{H}_{2} \mathrm{O} / \mathrm{cm}^{3}$ and $0.358 \mathrm{~g} \mathrm{H}_{2} \mathrm{O} / \mathrm{cm}^{3}$ ) and the thickness of the $18-\mathrm{m}$-diam deposits (about $2.48 \mathrm{~m}$ and $0.942 \mathrm{~m}$ ), the volumes of water to be evaporated were determined to be about $2.8 \times 10^{4} \mathrm{~L}$ and $8.6 \times 10^{4} \mathrm{~L}$ for the LCF and HCF, respectively. Thus the fission yields were estimated to be about $2.8 \times 10^{21}$ fissions for the LCF and $8.6 \times 10^{21}$ fissions for the HCF. Note that the yields for the HCF scenario are about a factor of 2 larger than the values reported in ref. 1 due to an error in the determination of the amount of water present. No credit was taken for the heat capacity of the soil that would increase the fission yields by a small fraction. 
Table 1. Selected SiO,-soil results

\begin{tabular}{|c|c|c|c|c|c|c|c|c|c|c|c|}
\hline \multirow[b]{2}{*}{$\begin{array}{l}\text { Conc. } \\
\text { factor }\end{array}$} & \multicolumn{2}{|c|}{${ }^{23 s} \mathrm{U}$ content } & \multicolumn{2}{|c|}{ Water content } & \multirow[b]{2}{*}{ k. } & \multicolumn{2}{|c|}{ Critical infinite slab" } & \multicolumn{2}{|c|}{$\begin{array}{r}\text { Critical infinite } \\
\text { cylinder }\end{array}$} & \multicolumn{2}{|c|}{ Critical sphere" } \\
\hline & $\begin{array}{l}\mathrm{g}^{235} \mathrm{U} \\
\text { per } \\
\mathrm{cm}^{3}\end{array}$ & $\begin{array}{c}\mathrm{g}^{25 \mathrm{U}} \\
\mathrm{per} \\
\mathrm{g} \mathrm{S}-\mathrm{S}\end{array}$ & $\begin{array}{c}\mathrm{g} \mathrm{H}_{2} \mathrm{O} \\
\text { per } \\
\mathrm{cm}^{3}\end{array}$ & $\begin{array}{c}\mathrm{g} \mathrm{H}_{2} \mathrm{O} \\
\text { per } \\
\mathrm{g} \mathrm{S}-\mathrm{S}\end{array}$ & & $\begin{array}{l}\text { Thick- } \\
\text { ness } \\
\text { (cm) }\end{array}$ & $\begin{array}{c}{ }^{233} \mathrm{U} \\
\text { areal } \\
\text { density } \\
\left(\mathrm{kg} / \mathrm{m}^{2}\right)\end{array}$ & $\begin{array}{l}\text { Diameter } \\
\text { (cm) }\end{array}$ & $\begin{array}{c}{ }^{20 s} \mathrm{U} \\
\text { linear } \\
\text { density } \\
(\mathrm{kg} / \mathrm{m})\end{array}$ & $\begin{array}{l}\text { Diameter } \\
(\mathrm{cm})\end{array}$ & $\begin{array}{l}{ }^{203} \mathrm{U} \\
\text { mass } \\
\text { (kg) }\end{array}$ \\
\hline 3.0 & 0.0018 & 0.0011 & 0 & 0 & 1.06 & 367.13 & 6.608 & 621.5 & 54.607 & 844.74 & 568.12 \\
\hline 3.0 & 0.0018 & 0.0011 & 0.058 & 0.03625 & 0.894 & & & & & & \\
\hline 3.0 & 0.0018 & 0.0011 & 0.119 & 0.07438 & 0.751 & & & & & & \\
\hline 3.0 & 0.0018 & 0.0011 & 0.183 & 0.114375 & 0.642 & & & & & & \\
\hline 3.0 & 0.0018 & 0.0011 & 0.251 & 0.156875 & 0.556 & & & & & & \\
\hline 3.0 & 0.0018 & 0.0011 & 0.324 & 0.2025 & 0.487 & & & & & & \\
\hline 3.0 & 0.0018 & 0.0011 & 0.4 & 0.25 & 0.431 & & & & & & \\
\hline 10.5 & 0.0063 & 0.0039 & 0 & 0 & 1.512 & 94.21 & 5.935 & 205.28 & 20.851 & 303.38 & 92.109 \\
\hline 10.5 & 0.0063 & 0.0039 & 0.058 & 0.03625 & 1.478 & 54.53 & 3.435 & 113.3 & 6.352 & 165.3 & 14.899 \\
\hline 10.5 & 0.0063 & 0.0039 & 0.119 & 0.07438 & 1.367 & 50.1 & 3.156 & 97.96 & 4.748 & 140.28 & 9.106 \\
\hline 10.5 & 0.0063 & 0.0039 & 0.183 & 0.114375 & 1.261 & 50.94 & 3.209 & 94.72 & 4.439 & 133.44 & 7.838 \\
\hline 10.5 & 0.0063 & 0.0039 & 0.251 & 0.156875 & 1.163 & 55.96 & 3.525 & 99.6 & 4.909 & 138.1 & 8.688 \\
\hline 10.5 & 0.0063 & 0.0039 & 0.324 & 0.2025 & 1.075 & 68.49 & 4.315 & 117.08 & 6.783 & 159.62 & 13.415 \\
\hline 10.5 & 0.0063 & 0.0039 & 0.4 & 0.25 & 0.995 & 111.87 & 7.048 & 174.66 & 15.094 & 246.4 & 49.347 \\
\hline
\end{tabular}

Using the models, methods, and sources described above, the dose results under the assumed fission yields for the HCF case (i.e., $8.6 \times 10^{21}$ fissions) and the LCF case (i.e., $2.8 \times 10^{21}$ fissions) were determined. The results are shown in Table 3 for all the analyzed conditions.

These results show that total doses are higher for the LCF case than for the HCF case by about $30 \%$. The total dose-per-fission values (not shown) for the LCF are about a factor of 4 higher than for the HCF. This higher dose is because the LCF deposit is thicker and therefore closer to the ground surface. This higher LCF dose per fission is offset by the LCF fission yield, which is about a factor of 3 smaller than the HCF fission yield.

Also, shown in Table 3 are the neutron and gamma-ray dose components. These values add to the total dose and are given primarily for completeness. Note that the neutron doses near the deposit account for about $60 \%$ of the total dose for both HCF and LCF cases, while the neutrons comprise about $80 \%$ of the total dose at the $90-\mathrm{m}$ location. Thus it appears that the neutron dose portion of the total dose increases with distance away from the deposit, although the total dose decreases at a rapid rate with increasing distance from the axis of the critical deposit.

Additional studies were performed to ensure the reliability of the results given in Table 2 . These studies included the use of SAS1 (both buckled and unbuckled) and MCNP. Figure 1 summarizes these studies. For horizontal distances less than $10 \mathrm{~m}$ from the center of the assumed disk source, the buckled SAS1 and MCNP solutions compare favorably while the DORT results are about a factor of two higher. This comparison is reasonable considering the DORT calculation of the leakage at the ground surface was determined from an effectively 1-D criticality problem, i.e., only the vertical transport was quantified, the horizontal dimension of the fissile deposit was infinite. The unbuckled SAS1 case shows the maximum effect in 1-D of the neglect of radial buckling and clearly envelops the DORT solution.

At horizontal distances greater than $10 \mathrm{~m}$, the SAS1 results are not valid since they do not include air scatter contributions and thus seriously underpredict the dose values. The DORT values remain about a factor of two conservative with respect to the MCNP values. 
Table 2. Dose results for assumed high and low CFs at locations near and far from potential critical deposits

\begin{tabular}{c|c|c|c|c}
\hline $\begin{array}{c}\text { High or low } \\
\text { concentration }\end{array}$ & $\begin{array}{c}\text { Distance }(\mathrm{m}) \text { from } \\
\text { deposit center }\end{array}$ & Neutron dose (rem) & $\begin{array}{c}\text { Gamma-ray dose } \\
\text { (rem) }\end{array}$ & $\begin{array}{c}\text { Total dose } \\
\text { (rem) }\end{array}$ \\
\hline High & 0 & 72.2 & 45.5 & 117.7 \\
Low & 0 & 98.6 & 58.8 & 157.4 \\
High & 90 & 0.094 & 0.025 & 0.119 \\
Low & 90 & 0.131 & 0.034 & 0.165 \\
\hline
\end{tabular}

${ }^{2}$ All detector locations assumed to be one meter above the ground.

'ANSU/ANS-6.1.1-1977, 1977.

\section{CONCLUSIONS}

Evaluations based upon licensed soil-contamination limits specified for Envirocare revealed a theoretical possibility of a nuclear criticality accident, given reasonable soil assumptions and hydrogeochemical influences on the concentration of SNM, specifically ${ }^{235} \mathrm{U}$. However, reviews of disposal/burial records from Envirocare reveal that concentrations of ${ }^{233} U$ in the waste material are more than a factor of 10 less than licensed concentrations of ${ }^{235} U$ and that the average enrichment is below the minimum $1 \%$ required to achieve nuclear criticality. Thus the likelihood of a criticality accident is vanishingly small.

Even though the probability of a criticality is small, the dose results given in this work predict the radiation levels expected from such an event. They are presented as integrated dose which represents the dose expected if a person remained at that location during the entire duration of the event. No attempt was made to quantify dose rate levels. The length of time required to concentrate uranium is expected to be long (e.g., 100-10,000 years). This slow approach to criticality will further mitigate rapid approaches to critical or supercritical conditions.

These dose values are relatively low considering the postulated large magnitude of the fission yield. Doses from the two scenarios considered are quite comparable, indicating little sensitivity to specific configurations.

\section{REFERENCES}

1. L. E. Toran, C. M. Hopper, M. T. Naney, C. V. Parks, J. F. McCarthy, and B. L. Broadhead, The Potential for Criticality Following Disposal of Uranium at Low-Level Waste Facilities Volume 1: Uranium Blended with Soil, NUREG/CR-6505, Vol. 1 (ORNL/TM-13323/V1), Lockheed Martin Energy Research Corp., Oak Ridge Natl. Lab., 1996.

2. Utah Department of Environmental Quality, Division of Radiation Control, Radioactive Material License, UT 2300249 to Envirocare of Utah, Inc., 1995.

3. G. Sposito, The Chemistry of Soils, Oxford University Press, New York, 1989.

4. SCALE: A Modular Code System for Performing Standardized Computer Analyses for Licensing Evaluations, NUREG/CR-0200, Rev. 4 (ORNL/NUREG/ CSD-2/R4), Vols. I-III, available from the Radiation Shielding Information Center as CCC-545, 1995.

5. G. Tuck, "Simplified Methods of Estimating the Results of Accidental Solution Excursions," Nucl. Technol. 23, 177-199 (1974).

6. W. A. Rhoades and R. L. Childs, "The DORT Two-Dimensional Discrete Ordinates Code," Nucl. Sci. Eng. 99, 88-89 (1988).

7. Los Alamos Monte Carlo Group, MCNP - A General Monte Carlo Code for Neutron and Proton Transport, LA7396-M, Los Alamos Natl. Lab., September 1986. 


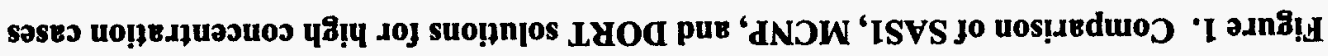

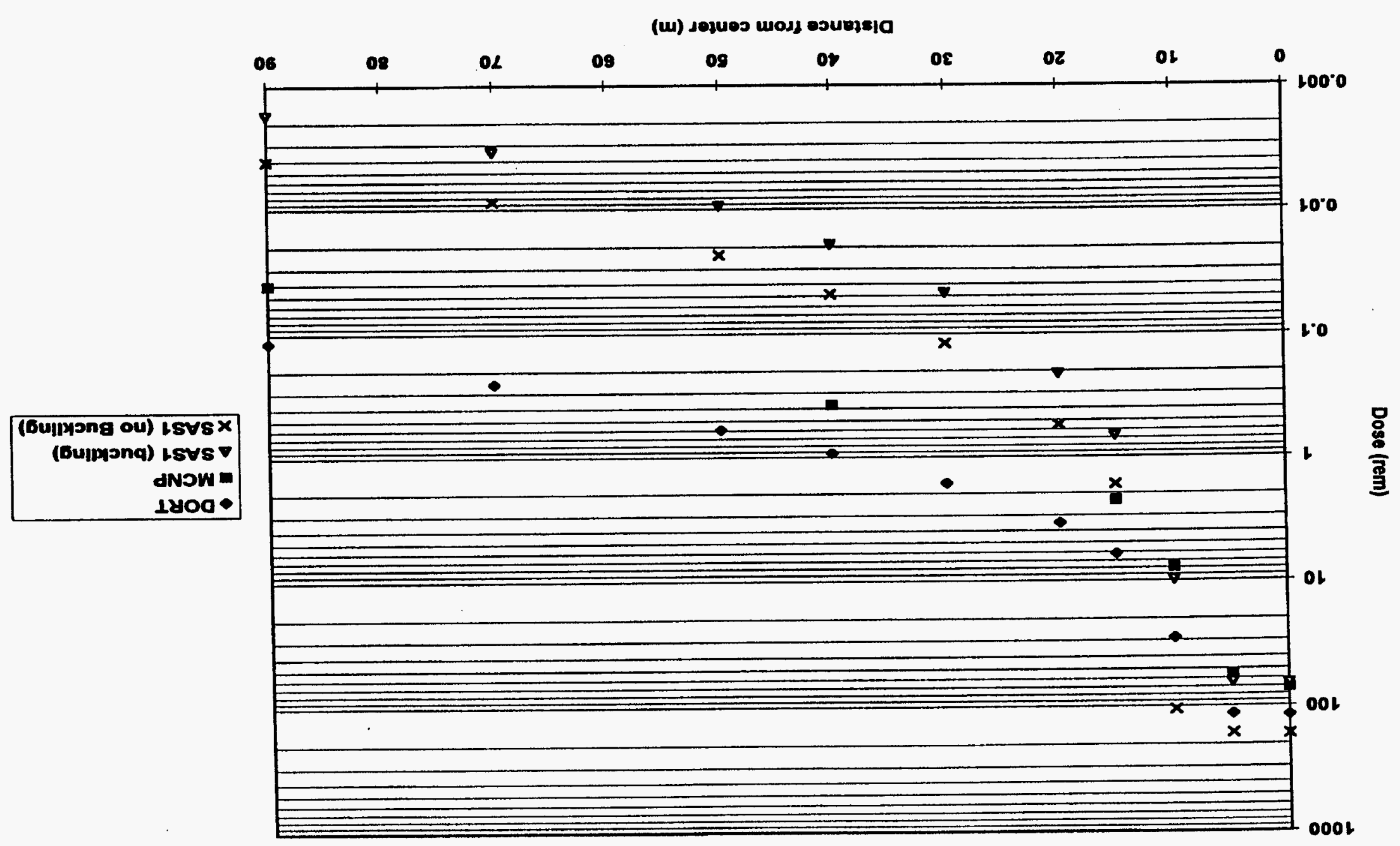

spoypew yodsued jo uospedwos 


\section{Manuscript Information File}

Log number 66

Dose Consequences From a Postulated Criticality Occurring in a Low-Level Waste Disposal Facility author

Broadhead Bryan L.

Oak Ridge National Lab

Bldg 6011, MS 6370

Oak Ridge, TN 37831-6370

423/576-4476

423/576-3513

bub@ornl.gov

end author

author

Childs Robert $L$.

Oak Ridge National Lab

Bldg 6011, MS 6370

Oak Ridge, TN 37831-6370

423/574-4121

423/576-3513

rlc@oml.gov

end author

author

Hopper Calvin M.

Oak Ridge National Lab

Bidg 6011, MS 6370

Oak Ridge, TN 37831-6370

423/576-8617

423/576-3513

fhh@ornl.gov

end author

author

Parks Cecil V.

Oak Ridge National Lab

Bldg 6011, MS 6370

Oak Ridge, TN 37831-6370

423/574-5280

423/576-3513

cvp@ornl.gov

end author

Criticality

Dose Consequence

Low-Level Waste 


\section{M98003172 \\ ||||||||||||||||||||||||||||||||||||||||||||||||||||||||}

Report Number (14)ORNL /CP $=-96093$
CONF -980.903

Jubl. Date (11) $\frac{19 Q 7 / Q}{N R C, X F}$
sponsor Code (18)
JC Category (19) $L Q C=O Q Q Q, D O E / E R$ 